\title{
Preparing Malaysian vocational and technology teachers to integrate computer technology in teaching vocational and technology subjects
}

\begin{abstract}
A study was conducted in three selected states in Malaysia to determine the preparedness of vocational and technology teachers to integrate computer technology in their classrooms. The study showed that teachers did not have a high level of general knowledge about computers (mean=6.3, sd.=2.97). They were not very knowledgeable in some computer software. They thought that they were not skillful in using computer software such as electronic spreadsheet (57.1\%), word-processing and desktop publishing (50.8\%), and database management (67.9\%). Almost two-thirds of the respondents cannot do programming. Realizing that they did not have the necessary knowledge and skills, the majority of the teachers would like to attend training in using computers for instruction.
\end{abstract}

Keyword: Vocational and technology teachers; Computer technology; Preparedness 